\title{
Control of Thermo-Acoustics Instabilities: The Multi-Scale Extended Kalman Approach
}

Dzu K. Le, John C. DeLaat, and Clarence T. Chang

Glenn Research Center, Cleveland, Ohio 
Since its founding, NASA has been dedicated to the advancement of aeronautics and space science. The NASA Scientific and Technical Information (STI) Program Office plays a key part in helping NASA maintain this important role.

The NASA STI Program Office is operated by Langley Research Center, the Lead Center for NASA's scientific and technical information. The NASA STI Program Office provides access to the NASA STI Database, the largest collection of aeronautical and space science STI in the world. The Program Office is also NASA's institutional mechanism for disseminating the results of its research and development activities. These results are published by NASA in the NASA STI Report Series, which includes the following report types:

- TECHNICAL PUBLICATION. Reports of completed research or a major significant phase of research that present the results of NASA programs and include extensive data or theoretical analysis. Includes compilations of significant scientific and technical data and information deemed to be of continuing reference value. NASA's counterpart of peerreviewed formal professional papers but has less stringent limitations on manuscript length and extent of graphic presentations.

- TECHNICAL MEMORANDUM. Scientific and technical findings that are preliminary or of specialized interest, e.g., quick release reports, working papers, and bibliographies that contain minimal annotation. Does not contain extensive analysis.

- CONTRACTOR REPORT. Scientific and technical findings by NASA-sponsored contractors and grantees.
- CONFERENCE PUBLICATION. Collected papers from scientific and technical conferences, symposia, seminars, or other meetings sponsored or cosponsored by NASA.

- SPECIAL PUBLICATION. Scientific, technical, or historical information from NASA programs, projects, and missions, often concerned with subjects having substantial public interest.

- TECHNICAL TRANSLATION. Englishlanguage translations of foreign scientific and technical material pertinent to NASA's mission.

Specialized services that complement the STI Program Office's diverse offerings include creating custom thesauri, building customized databases, organizing and publishing research results ... even providing videos.

For more information about the NASA STI Program Office, see the following:

- Access the NASA STI Program Home Page at http://www.sti.nasa.gov

- E-mail your question via the Internet to help@sti.nasa.gov

- Fax your question to the NASA Access Help Desk at 301-621-0134

- Telephone the NASA Access Help Desk at 301-621-0390

- Write to: NASA Access Help Desk NASA Center for AeroSpace Information 7121 Standard Drive Hanover, MD 21076 


\section{Control of Thermo-Acoustics Instabilities: The Multi-Scale Extended Kalman Approach}

Dzu K. Le, John C. DeLaat, and Clarence T. Chang Glenn Research Center, Cleveland, Ohio

Prepared for the

39th Joint Propulsion Conference and Exhibit cosponsored by the AIAA, ASME, SAE, and ASEE Huntsville, Alabama, July 20-23, 2003

National Aeronautics and

Space Administration

Glenn Research Center 


\section{Acknowledgments}

The authors sincerely thank Dr. Daniel Paxson and Mr. Daniel Vrnak for their efforts in model and simulation developments to validate this control design. We also greatly appreciate the contributions of the United Technology Research Center team to this research, especially Dr. Andrzej Banaszuk, for his invaluable insights and modeling data. Funding support for this work has been provided by the NASA Smart Efficient Components Project through the help of Project manager, Robert Corrigan, with partial support for advanced control developments by the Strategic Research Fund (SRF) and the Aerospace Flywheel Technology Program.

\section{Document Change History}

This printing, numbered as NASA/TM-2003-212536/REV1, October 2003, replaces the previous version, NASA/TM-2003-212536, August 2003. The reference numbers on page 3, paragraph 4, line 6, have been changed.

The Propulsion and Power Program at

NASA Glenn Research Center sponsored this work.

Available from

NASA Center for Aerospace Information 7121 Standard Drive Hanover, MD 21076
National Technical Information Service 5285 Port Royal Road Springfield, VA 22100 


\title{
CONTROL OF THERMO-ACOUSTICS INSTABILITIES: THE MULTI-SCALE EXTENDED KALMAN APPROACH
}

\author{
Dzu K. Le, John C. DeLaat, and Clarence T. Chang \\ National Aeronautics and Space Administration \\ Glenn Research Center \\ Cleveland, Ohio
}

\begin{abstract}
"Multi-Scale Extended Kalman" (MSEK) is a novel modelbased control approach recently found to be effective for suppressing combustion instabilities in gas turbines. A control law formulated in this approach for fuel modulation demonstrated steady suppression of a high-frequency combustion instability $(>500 \mathrm{~Hz})$ in a liquid-fuel combustion test rig under engine-realistic conditions. To make-up for severe transport-delays on control effect, the MSEK controller combines a "wavelet"-like "Multi-Scale" analysis and an "Extended Kalman Observer" to predict the thermo-acoustic states of combustion pressure perturbations. The commanded fuel modulation is composed of a damper action based on the predicted states, and a tones suppression action based on the Multi-Scale estimation of thermal excitations and other transient disturbances. The controller performs automatic adjustments of the gain and phase of these actions to minimize the Time-Scale Averaged Variances of the pressures inside the combustion zone and upstream of the injector. The successful demonstration of Active Combustion Control with this MSEK controller completed an important NASA milestone for the current research in advanced combustion technologies.
\end{abstract}

\section{INTRODUCTION}

Combustor instability control is an enabling technology for superior engine performance. Acoustic resonances driven by heat release fluctuations can produce large pressure oscillations inside the combustion chamber. ${ }^{1}$ These thermoacoustic instabilities can potentially lead to premature mechanical failures. In the quest to reduce particulate and $\mathrm{NOx}$ emission, future aero-engine combustors will likely have lean-burning front-ends. As the ground-based gas-turbine field has experienced, however, lean-burning combustors are more susceptible to combustion instabilities due to the more homogeneous transmission medium (an environment favorable for the forming of distinct acoustics modes); less damping from reduced or eliminated liner film cooling; and more energetic perturbation sources from the more vigorous fuel-air mixing.

Active control of combustion instabilities by properly-phased fuel modulation is a very promising method for instability control in aero-engines. Conceptually, control of combustion instability pressure can be achieved by other means $2, \ldots, 14$. However, these other means (e.g., speaker actuation) tend to be bulky, have limited operating range, or have other undesirable side effects. In comparison, liquid fuel modulation is compact, more practical, and can deliver the most energy with the least effort.

The NASA Glenn Research Center (GRC) Active Combustion Control (ACC) technology effort aims to demonstrate active control in a realistic and relevant environment by providing experiments tied to aircraft gas-turbine engines. The first successful demonstration of active control of a High Frequency $(\mathrm{HF} ;>500 \mathrm{~Hz})$ thermo-acoustic instability via fuel modulation under engine-realistic conditions was accomplished in June 2002 by the NASA GRC effort. It was reaffirmed in September 2002 with additional experiments and improved results. These experiments were done in collaboration with Pratt Whitney 14,15,16 at the United Technology Research Center (UTRC), on the NASA Single Nozzle Combustion Rig (SNR).

Prior to this work, partial successes with suppression via fuel modulation of Low Frequency instability (LF; $\sim 280 \mathrm{~Hz}$ ) had been reported elsewhere, including the works supported by NASA. ${ }^{26,27}$ In these earlier attempts to suppress the dominant instabilities, other instability peaks would arise around the central frequency (so-called "peak splitting" ${ }^{\mathbf{2 6 , 2 7}}$ as seen on the pressure amplitude spectra plot, Figure 1). A solution to this problem, which occurs even with moderate control gains, has not been identified in previous works ${ }^{8, \ldots, 14}$. For this effort, active instability suppression has been demonstrated for high-frequency oscillations on the NASA SNR. This HF

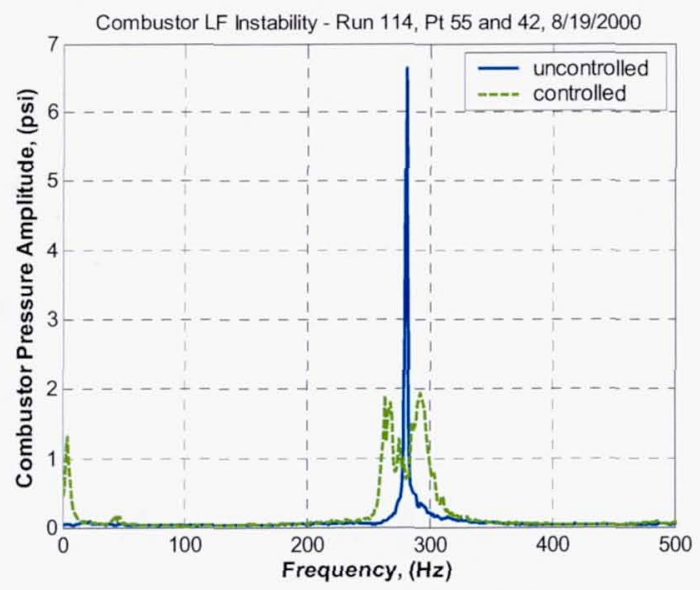

Figure 1: Low-frequency instability suppression control, showing peak-splitting ${ }^{26}$ 


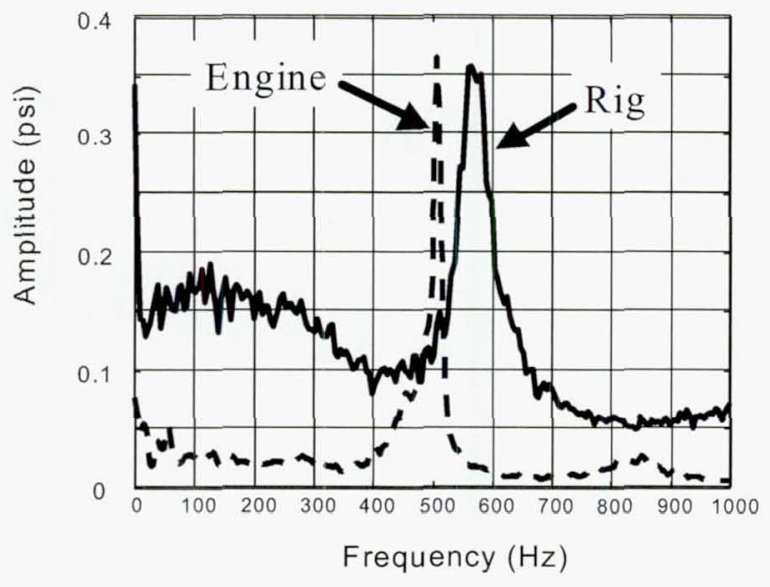

Figure 2: Engine and NASA Single Nozzle Combustion Rig Comparison

instability in the NASA SNR represents an actual case of engine instability although the rig exhibits higher background noise/disturbance levels than the engine (Figure 2). The NASA SNR operates at engine pressures, temperatures, and flows using liquid jet fuel and incorporates many engine-like features including an actual engine fuel injector (Figures 3 and 4). ${ }^{14,15,16}$

This successful demonstration of ACC for the HF case was carried out with two distinct controllers developed by NASA: an adaptive controller by Kopasakis ${ }^{17}$ and an observer-based controller by Le in the Multi-Scale Extended Kalman (MSEK) approach described herein. The two controllers yielded comparable results, and neither showed any sign of "peaksplitting". This paper is devoted to the MSEK model-based controller.

In this paper, a brief introduction to the MSEK control approach is given. Next, the MSEK control design approach is illustrated with a detailed description of the controller developed for the experimental demonstration of combustion

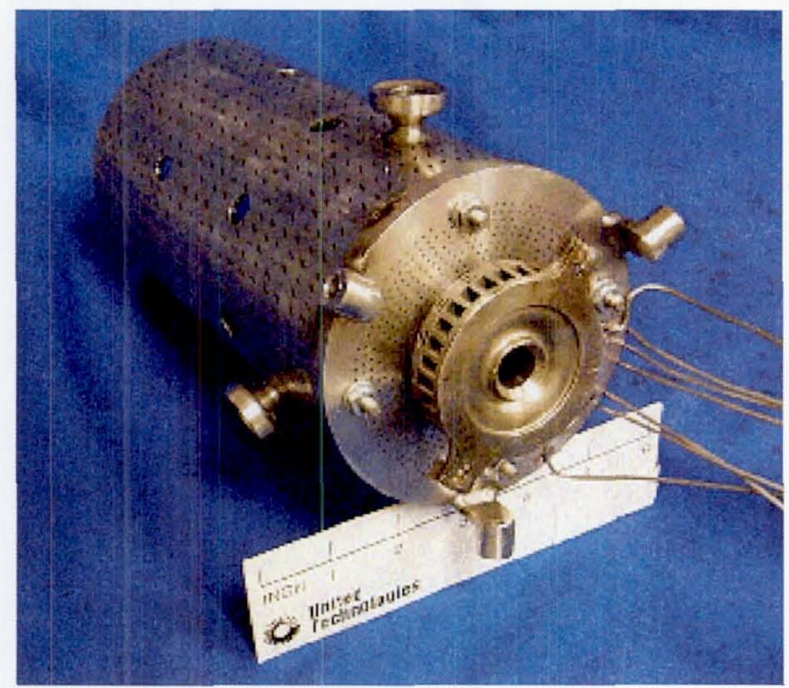

Figure 3: Combustor Rig for Combustor Instability Control Research (Photo by United Technologies Research Center) instability control. Results of the evaluation of the controller via numerical simulation are presented followed by the experimental results with the combustor rig. Finally, a generalization of this MSEK controller and some concluding remarks are given.

\section{THE MULTI-SCALE EXTENDED KALMAN CONTROL APPROACH}

State variables tracking and optimal control normally can be handled effectively by Kalman Filters and the LQR method ${ }^{18}$ only if the system dynamics are fairly close to the classical case of stochastic processes. These classical control methods are often found inadequate for aero-engines or other complex systems with a high level of dynamic uncertainties, complex (external or internal) disturbances, noise, and transport delays in the control mechanisms. Examples of such complex disturbances include: mass-imbalance; sensor distortion; highorder or nonlinear behaviors of rotor, motor, and bearing dynamics; unknown excitations of thermo-acoustics instabilities; and higher-order stall and surge dynamics; etc. A feasible solution for many such difficult cases is to predict the variations in system transient characteristics with Multi-scale Analysis (e.g., with the Wavelet Transform ${ }^{19,20,21,22}$ ) to adjust model and control parameters accordingly, and to compensate the control commands for unknown, transient disturbances.

That direction for control design was proposed by $\mathrm{Le}^{21}$ and named the Multi-Scale Extended Kalman approach in this paper. It was inspired by the fact that, non-stationary processes (e.g., the Fractional Brownian Motions) become stationary under proper wavelet transformations. ${ }^{20}$ So, MultiScale Analysis promises a relief from the limitations of Kalman filters, which provide optimal estimation solutions only to stationary processes (e.g.; linear system driven by white-noise -- a stationary random process). The mathematics foundation for Wavelets representation of (non-trivial) random processes was established by Houdre ${ }^{20}$ in 1993. Implicit in Houdre results is the advantage of minimizing estimation errors or system outputs variance after a proper wavelet transformation of the related random processes onto the timescale domain. Thus, the ensemble variance (or a timeaveraged approximation of the variance) of system outputs -the usual optimization criteria in the classical Kalman approach -- would be replaced in the MSEK approach by the time-scale averaged variance (limited to selected ranges of signal details or "scales") of the transformed signals.

The MSEK method has been found to be effective for many difficult problems where it is necessary to track system states with high accuracy despite disturbances, system uncertainties, and non-linearity. This approach requires state-variable estimation for the system dynamics specially formulated in the general framework of an Extended Kalman Observer - i.e., extensions of the Classical Kalman Filter technique to handle the nonlinear and time-varying natures of complex systems ${ }^{23}$. In addition, wavelet-like, Multi-Scales models instead of the ordinary Fourier bases are integrated into the Extended Kalman Observer to estimate system disturbances. The inclusion of these Multi-Scales disturbance models and Multi- 


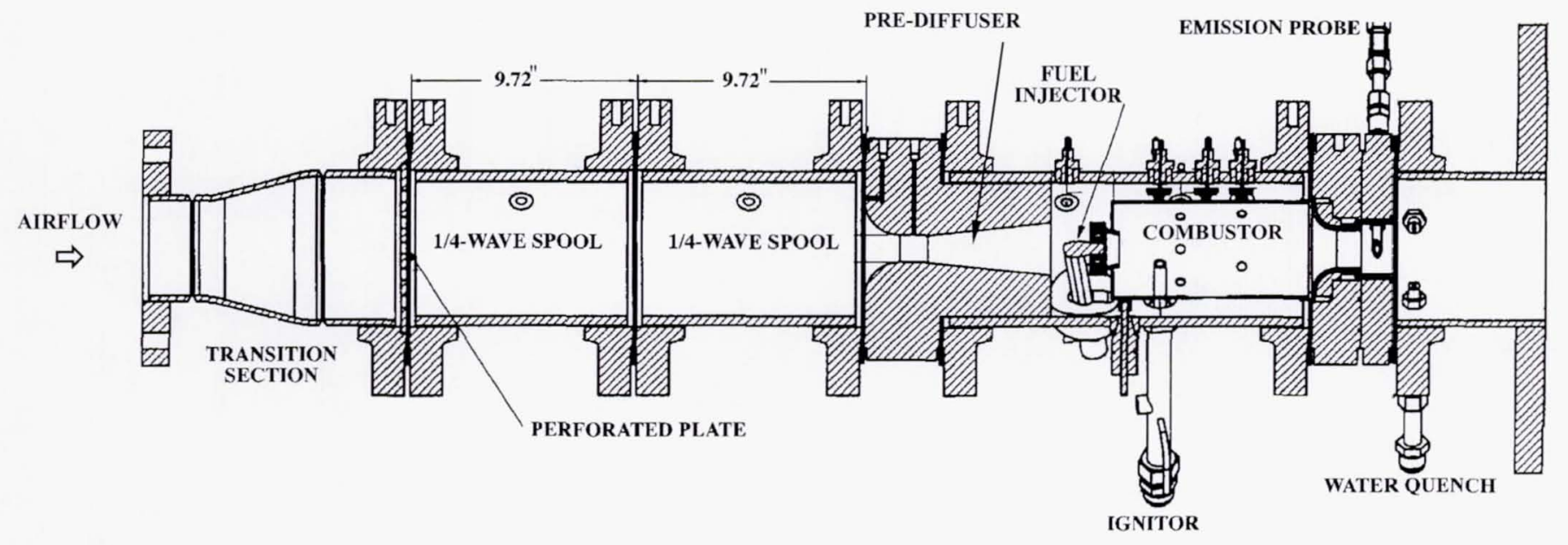

Figure 4: Schematic of the NASA SNR Combustion Rig installed at UTRC

Scale analysis into the Extended Kalman system state equations allows for effective suppression of transient disturbances as well as adjustment of observation and other control parameters against system uncertainties.

Multi-Scale signal-processing techniques are versatile and powerful for analyzing both transient and steady dynamics. Wavelet bases, for example, provide coherent building blocks for signal analysis and synthesis. They, however, are too computationally intensive for use in real-time monitoring or control. Approximations and simplifications of various wavelets and associated algorithms are necessary to reduce computation time. Nevertheless, for many challenging applications, such customized implementation of Multi-Scale techniques still provides greater versatility and accuracy than does the Fourier Transform approach. Practical wavelets such as the Compact Harmonic Wavelets ${ }^{22}$ are effective for estimating and compensating for quasi-periodic, complex disturbances, or for fine-tuning Kalman filters.

So, in this method the Multi-Scale digital filters are used to calculate the "Time-Scale-Averaged Variances" of system outputs as performance metrics for real-time tuning of model and control parameters. Such Multi-Scale Performance Metrics effectively differentiate competing parameters (with a generally well-conditioned Jacobian on the parameter space), allowing for sequential search and adjustment of their optimal values.

This new control design approach and several practical MultiScale analysis algorithms were developed for system identification and real-time tuning of model and control parameters, ${ }^{21,} 22$ and have been successfully applied since 1999 to the control of magnetically levitated, high-energy flywheels. ${ }^{24,28}$ Several test rigs of representative problems in engine and rotating machinery were used in the development of various techniques to combine Multi-Scale Analysis with Extended Kalman filters to estimate transient disturbances and enhance system states tracking.

\section{A MSEK CONTROL DESIGN FOR ACC}

A Phase-Shifting Proportional scheme alone, even one with phase-drift adjustments, is only effective against relatively steady harmonic excitations. For combustion instability control, the highly transient thermal excitations and other unknown disturbances will induce side-lobes ("peak-splitting') and hence severely reduce the effectiveness of the controller in damping out the acoustic modes. ${ }^{27}$ This motivates the following control design strategy:

(a) A Predictive Extended Kalman Filter to reduce the adverse effect of large transport-delays and random disturbances for effective damping of the acoustic modes.

(b) A parallel Tone Suppression scheme with varying gain and phase to counter thermal excitations and other unknown harmonic disturbances.

This paper will describe the numerical validation and empirical demonstration of the control strategy as summarized by (a) and (b). A more thorough presentation of the mathematical fundamentals underlying the MSEK control design is expected to be published in the near future.

The algorithms and implementation of (a) and (b) are presented in the next three sub-sections, beginning with a functional overview. Figure 5 shows a top level functional diagram of the digital controller for ACC named Multi-Scale Predictive Damper (MSPD) designed in the MSEK approach.

\section{$\underline{\text { 3.1. Design Functional Overview }}$}

The greatest challenge for combustion instability control is to overcome the inherent, large time-delays on fuel modulation effects under severe disturbances (random as well as harmonic). The total time-delay could be longer than three oscillation cycles of instability. Thus, it is necessary to have a Kalman-type predictor for the dominant acoustics states -Sub-block "EK States Predictor" in Figure 5. In the Predictor, 


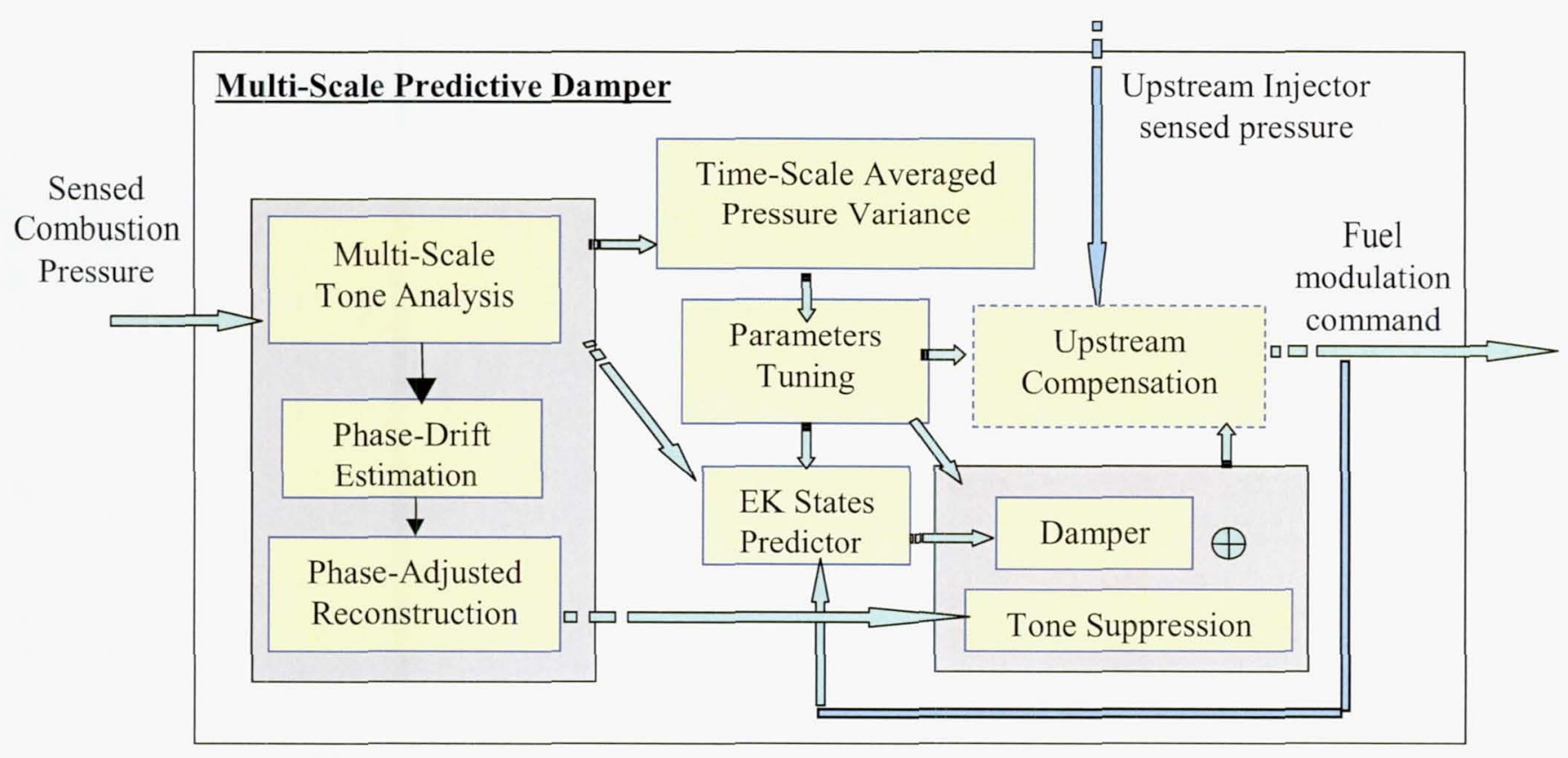

Figure 5: Multi-Scale Predictive Damper (MSPD) functional block diagram

the modeled dynamics of combustion pressure oscillations include the effects of (non-linear) heat release fluctuations. Inputs to the Predictor are not the combustion zone sensed pressure, but rather the "tones" extracted from it by a MultiScale Tones Analysis scheme, as will be explained in the following sub-sections. The fuel modulation command includes a proportional component intended for damping out the dominant acoustic modes based on the Predictor and a non-linear component (Tone-Suppression) for countering thermal excitations and other transient disturbances. These excitations are estimated by a phase-adjusting Multi-Scale tones extraction scheme (Phase-Adjusted Reconstruction). The adjustments for phase drifts are calculated by a regression scheme (Phase-Drift Estimation). Besides the phase-adjusted tones, the Multi-Scale Analysis function in MSPD also calculates the Time-Scale Averaged Pressure Variance which is used as a performance metric for automatic global search of optimal parameter ranges (Parameters Tuning) and adjustments (e.g., control phases and gains, and predictor parameters). The compensation for undesirable pressure disturbances from the fuel line just upstream of the injector (Upstream Compensation) is also a damper.

\subsection{Tone "Quadratures" Extraction}

The purpose of the Multi-Scale Tone Analysis block in MSPD is to extract predictable, transient characteristics in the pressure measurements for control input. It was found that, the Single Nozzle Combustion Rig (SNR) might exhibit either the LF $(\sim 285 \mathrm{~Hz})$ or $\mathrm{HF}(>500 \mathrm{~Hz})$ oscillations depending on the length and location of one of the two spool sections (upstream airflow) relative to the pre-diffuser. Figure 4 shows the HF configuration of the Combustion Rig, for which both spools are upstream of the pre-diffuser that flows into the combustor dome. The Tone Analysis part of controller MSPD (Figure 5) is performed by wavelet-like filters to extract the wavelet "quadratures" of the "tones" in the sensed pressures, in a vicinity of the two frequencies.
By definition, a "quadratures" pair of a signal stream $s(t)$ in a frequency band is any decomposition of the signal contents of that band into two orthogonal components $\mathrm{s}_{1}(\mathrm{t})$ and $\mathrm{s}_{2}(\mathrm{t})$ by using an Orthogonal Wavelets Decomposition and Reconstruction scheme (e.g., using "quadrature mirror filters"). ${ }^{19}$ In this strict definition of signal "quadratures", the mutual- orthogonality condition imposed on $s_{1}(t)$ and $s_{2}(t)$ is understood in the sense of $\mathrm{L}_{2}$-Function Inner-Product and is automatically satisfied even for the finite support intervals of the Orthogonal Wavelets of choice.

For simplicity, instead of a formal Orthogonal Wavelet Decomposition and Reconstruction scheme, a pair of Finite Impulse Response (FIR) band-pass filters is designed for each frequency band to extract the signal (approximate) "quadratures"; one filter for extracting $\mathrm{s}_{1}(\mathrm{t})$ with a phase lead of 45 degrees at the center frequency of interest, and the other for $s_{2}(t)$ with a phase lag of 45 degrees; the gains of both filters are equal to 1 at the central frequency. The advantage of these multi-scale (approximate) "quadrature filters" is in their simplicity; also, the polar angle of the vector $\left[\mathrm{s}_{1}(\mathrm{t}) \mathrm{s}_{2}(\mathrm{t})\right]^{t}$ $\left([\ldots]^{t}\right.$ denotes a transposed matrix) represents the instantaneous "phase" angle of the extracted tone plus $\pi / 4$ radians.

Notes: (1) In other Multi-Scale Analysis applications, "Quadrature Filter Banks", such as the Compact Harmonics Wavelets, ${ }^{22}$ are needed for extracting multiple tones from the raw signals.

(2) The "Wavelet"-Fourier-Analysis connection: Roughly speaking, a "frequency band" of the Fourier Transform corresponds to a "wavelet subspace" composed of a certain range of "feature scales" (or signal "details") of the Wavelet Transform. The higher the frequency band, the smaller the corresponding feature scales are. 


\subsection{Quadratures Prediction}

Throughout this paper, $\boldsymbol{S}_{n}$ denotes the $4 \times 1$ vector of the "quadrature pairs" $S_{n} \equiv\left[\begin{array}{l}S_{n}^{1} \\ S_{n}^{2}\end{array}\right]$ of tone 1 and tone 2 extracted from the sensed combustor chamber pressure oscillations (LF and HF tones, respectively; with the superscript as the tone index and " $n$ " as the time index). The following approximate "evolution model" (Equations (1-a) to (1-f)) for the combustion pressure quadratures at $N$ sampling steps ( control-delay time) ahead of the "current" time index " $n$ " was used for the formulation of the predictor (See Appendix: Predicted Quadratures Evolution Model):

$$
\begin{aligned}
& \boldsymbol{S}_{N+n+1}=\mathrm{AS}_{N+n}+\mathrm{Q}+\mathbf{w} \\
& \boldsymbol{z}_{n+1}=\mathrm{U} \boldsymbol{z}_{n}+\mathrm{FM}_{\boldsymbol{S}_{N+n}} \\
& \boldsymbol{y}_{n}=\mathrm{E} \boldsymbol{z}_{n}+\mathrm{DM} \boldsymbol{S}_{N+n}+\mathbf{v} \\
& {\left[\begin{array}{l}
p_{1} \\
p_{2}
\end{array}\right] \equiv\left[\begin{array}{llll}
\mathrm{h}_{11} & 0 & \mathrm{~h}_{12} & 0 \\
\mathrm{~h}_{21} & 0 & \mathrm{~h}_{22} & 0
\end{array}\right] \boldsymbol{S}_{n}+\left[\begin{array}{l}
b \\
b
\end{array}\right] u_{n}}
\end{aligned}
$$

with limits: $-p_{\max } \leq p_{i} \leq p_{\max }$

$$
\begin{aligned}
& \left.Q_{i}=\kappa\left(\sqrt{\left(p_{i} / p_{o}\right)+1}-1\right) \text { (for } i=1,2\right) \\
& Q \equiv\left[\begin{array}{llll}
0 & Q_{1} & 0 & Q_{2}
\end{array}\right]^{t}
\end{aligned}
$$

The "output measurement" in these equations is a $2 \times 1$ vector $\boldsymbol{y}_{n}$ representing the combined quadratures of mode 1 and mode 2 extracted from combustor pressure measurement at time index " $n$ " for input to the Kalman predictor. That is,

$$
\mathbf{y}_{n}=\mathrm{MS}_{n}
$$

$M=\left[\begin{array}{llll}1 & 0 & 1 & 0 \\ 0 & 1 & 0 & 1\end{array}\right]$

The large time-index shift from $\boldsymbol{S}_{N+n}$ to the feedback $\boldsymbol{y}_{n}$ was approximated by a 5 th-order Pade approximation. That is, in Equations (1-b) and (1-c), $\boldsymbol{y}_{n}$ was viewed as the result of a $5^{\text {th }}$ order Pade-transform (for a time-delay $\sim N \times \mathrm{T}$; $\mathrm{T}$ denotes the sampling time) applied on the $2 \times 1$ vector M $\boldsymbol{S}_{N+n}$. So, U, F, E, D are just the combined state matrices of the pair of Padetransformations used (with the respective dimensions $10 \times 10$, $10 \times 2,2 \times 10$, and $2 \times 2$ ). The quantities $\mathbf{v}$ and $\mathbf{w}$ are bandlimited random vectors.

$$
A=\left[\begin{array}{cc}
\left.\lambda_{1} \begin{array}{cc}
\cos \left(\omega_{1} T\right) & -\sin \left(\omega_{1} T\right) \\
\sin \left(\omega_{1} T\right) & \cos \left(\omega_{1} T\right)
\end{array}\right] & {[0]} \\
{\left[\begin{array}{lll}
0 & ]
\end{array}\right.} & \lambda_{2}\left[\begin{array}{cc}
\cos \left(\omega_{2} T\right) & -\sin \left(\omega_{2} T\right) \\
\sin \left(\omega_{2} T\right) & \cos \left(\omega_{2} T\right)
\end{array}\right]
\end{array}\right]
$$

with $\mathrm{T}$ being the sampling time; $\omega_{1}, \omega_{2}$ (in radians/sec) are the two tone frequencies; $\zeta_{1}, \zeta_{2}$ their open-loop damping coefficients; and $\lambda_{1}=\exp \left(-2 \zeta_{1} \omega_{1} \mathrm{~T}\right) ; \quad \lambda_{2}=\exp \left(-2 \zeta_{2} \omega_{2} \mathrm{~T}\right)$. The effect of combustion heat fluctuations on these acoustic quadratures (at $N$ steps ahead of $n$ ) is approximated by the vector-valued function $Q$ of $\boldsymbol{S}_{n}$ and the fuel modulation command $u_{n}$, as formulated in (1-d) to (1-f). The parameters $\left\{\mathrm{h}_{i j}\right\}$ are constant, internal feedback gains; $b$ the approximate control authority; $P_{\mathrm{o}}$, a reference pressure comparable to the mean pressure drop across the injector. The parameters $\left\{\mathrm{h}_{i j}\right\}, b, \kappa, p_{\max }$, and $N$ are chosen to match the open-loop forced response characteristics of the combustion chamber pressure.

The Kalman Quadratures Predictor: Equations (1-a) to (1-f) result in an estimation for $\boldsymbol{S}_{N+n}$, denoted by $\widehat{\boldsymbol{S}}_{n}$, formulated explicitly in Equations (4-a) to (4-e) below:

$$
\begin{aligned}
& \hat{\boldsymbol{S}}_{n+1}=\mathrm{A} \hat{\boldsymbol{S}}_{n}+\mathrm{Q}+\mathrm{K}_{1}\left(\mathrm{E} \hat{\boldsymbol{Z}}_{n}+\mathrm{DM} \hat{\boldsymbol{S}}_{n}-\mathrm{M} \boldsymbol{S}_{n}\right) \\
& \hat{\boldsymbol{Z}}_{n+1}=\mathrm{U} \hat{\boldsymbol{Z}}_{n}+\mathrm{FM} \hat{\boldsymbol{S}}_{n}+\mathrm{K}_{2}\left(\mathrm{E} \hat{\boldsymbol{Z}}_{n}+\mathrm{DM}_{\boldsymbol{S}}-\mathrm{MS}_{n}\right) \\
& {\left[\begin{array}{l}
p_{1} \\
p_{2}
\end{array}\right] \equiv\left[\begin{array}{llll}
\mathrm{h}_{11} & 0 & \mathrm{~h}_{12} & 0 \\
\mathrm{~h}_{21} & 0 & \mathrm{~h}_{22} & 0
\end{array}\right] \boldsymbol{S}_{n}+\left[\begin{array}{l}
b \\
b
\end{array}\right] u_{n}} \\
& \text { with limits: }-p_{\max } \leq p_{i} \leq p_{\max } \\
& Q_{\mathrm{i}} \equiv \kappa\left(\sqrt{\left(p_{i} / p_{o}\right)+1}-1\right) \quad(\text { for } i=1,2) \\
& Q \equiv\left[\begin{array}{llll}
0 & Q_{1} & 0 & Q_{2}
\end{array}\right]^{t} \text {. }
\end{aligned}
$$

The matrices $K_{1}$ and $K_{2}$ (of dimension $4 \times 2$ and $10 \times 2$, respectively) are the two vertical sub-blocks of the Kalman matrix computed from the evolution equations (1-a) to (1-c) for certain covariance matrices assumed for the random vectors $\mathbf{v}$ and $\mathbf{w}$ in these equations, treating $\mathrm{Q}$ as a known input at time " $n$ ". Note that, in this simplified estimator for $S_{N+n}$, the Kalman innovation term $^{18}$ was omitted. The numerical values of the parameters in Equations (4-a) to (4-e) will be presented in Section 4.

\section{4. Phase Bias and Drift Correction with Quadratures}

If $\boldsymbol{S} \equiv\left[s_{1}(t) s_{2}(t)\right]^{t}$ is the vector of quadratures extracted from a signal $\mathrm{s}(\mathrm{t})$ using "Quadrature Filters", then a combination $\mathbf{S}_{\alpha} \equiv\left(s_{1}(t) \cos \alpha-s_{2}(t) \sin \alpha\right)$ represents the tone of $\mathrm{s}(\mathrm{t})$ in the Quadrature bandwidth phase-shifted by " $\alpha+\pi / 4$ " radians. Thus, it might be used in a Proportional Phase-Shifting control scheme for a suitable phase bias " $\alpha$ ". But, a Proportional Phase-Shifting control with a fixed phase bias is not effective in handling large time-delays and phase drifts of transient or time-varying dynamics, especially when the Signal-to-Noise 
ratio is small. To remedy this, a regression scheme was used to estimate the drifts in the accumulated phase of each tone over the expected time interval of the total transport-delay.

\subsection{Damper Command}

A part of the fuel-modulation command $u_{n}$, essentially an LQR damper (distinguished by the superscript ' $d$ ' ) of fixed gain, is formulated as:

$u_{n}^{d^{\prime}}=\mu_{1} \hat{S}_{\beta_{1}}^{1}\left(t_{n}\right)+\mu_{2} \hat{S}_{\beta_{2}}^{2}\left(t_{n}\right)$,

where $\hat{S}_{\beta_{1}}^{1}\left(t_{n}\right)$ and $\hat{S}_{\beta_{2}}^{2}\left(t_{n}\right)$ are the signals constructed from each of the predicted quadratures as $2 \times 1$ sub-blocks in $\hat{S}_{n} \equiv\left[\begin{array}{l}S_{n}^{1} \\ \hat{S}_{n}^{2}\end{array}\right]$, using respective phase angles $\beta_{i} \equiv \bar{\beta}+\delta_{i n}$ (for the tone indices $\mathrm{i}=1,2$ ), where $\bar{\beta}$ is a fixed bias, $\delta_{i \mathrm{n}}$ the predicted phase-drift. The quantities $\mu_{1}$ and $\mu_{2}$ are fixed gains. The drifts $\delta_{i \text { n }}$ (over the time interval of expected control transport-delay, for tones $\mathrm{i}=1,2$ ) are predicted by a regression scheme applied on the quadrature phases $\left\{\alpha_{i n}\right\}$ as defined in Equation (6) of the next sub-section.

\subsection{Suppressions of Residual Harmonic Disturbances}

This part of the control scheme is to cancel out remaining harmonic disturbances that can not be suppressed by just the "damper". For this purpose, the instantaneous amplitudes and phases of the combustion pressure near the LF and HF are first estimated by projecting the quadratures $S_{n}^{i}$ (for $i=1,2$, as $2 \times 1$ vectors) onto an orthogonal frame rotating at the respective speed $\omega_{1}$. To reduce the effect of random noises, these projections are next passed through low-pass filters with cut-off frequencies at $100 \mathrm{~Hz}$ and $200 \mathrm{~Hz}$, respectively, before computing the amplitudes and phases. Note that these cut-off frequencies are about $1 / 3$ of the respective central frequencies. Consequently, the predicted pressure oscillations for the respective frequency bands are given by:

$$
\left.\sigma_{i}=r_{i n} \cos \left(\omega_{i} t_{n}+\alpha_{i \mathrm{n}}\right) \quad \text { (for } i=1,2\right)
$$

where $r_{i n}$ is the amplitude, and $\left\{\alpha_{i n}\right\}$ the polar angle at time $t_{n}$ of the filtered, projected quadrature vector.

Note that, $\sigma_{i}$ should be highly coherent with the unknown "residual" harmonic excitations other than white-noise disturbances and the heat quantities associated with expression (1-f). Therefore, to counter this unknown effect the fuelmodulation command $u_{n}$ is augmented with a compensation term (distinguished by the superscript ' $c$ ') of the following form, as computed in Tone Suppression:

$$
u_{\mathrm{n}}^{c^{\prime}}=\sum_{i=1,2} \gamma_{i \mathrm{n}} r_{i \mathrm{n}} \cos \left(\omega_{i} t_{n}+\alpha_{i \mathrm{n}}+\bar{\alpha}+\delta_{i \mathrm{n}}\right)
$$

(for tones $i=1,2$ ), where $\gamma_{i n}$ is an varying gain applied on $\sigma_{i}$ after it is phase-shifted by a bias $\bar{\alpha}$ plus $\delta_{i n}$. These gains are calculated as discrete values of this expression:

$$
\gamma_{i}=\gamma_{o}+\eta \int\left(r_{i}-\rho_{i}\right) d t \quad(\text { for } i=1,2),
$$

where $\gamma_{0}$ is a constant gain compatible to the expected control authority; $\eta$, a constant integral gain; $\rho_{i}$, a reduction level expected to be maintainable for $r_{i}$ with this scheme. Also, $\gamma_{0}$ 's are limited between certain bounds $\gamma_{\min }$ and $\gamma_{\max }$ before substituted into Equation (7).

\subsection{Fuel Modulation Command and Tuning}

Finally, expressions (5) and (7) combined gives the fuelmodulation command:

$$
u_{\mathrm{n}}=u_{\mathrm{n}}^{d^{\prime}}+u_{\mathrm{n}}^{c^{\prime}}
$$

In this control scheme, all the parameters in the predictor (as well as the control scheme) appear to be fairly deterministic and empirically predictable (at least for the SNR case), except for the phase biases, $\bar{\alpha}$ and $\bar{\beta}$, and the control authority represented by " $b$ " (see Equations (1-d)). These parameters are set by the Parameters Tuning logic in sequential global searches at low loop-gain. Once found, the average phase biases are adjusted with a slow-varying adjustment term $\varepsilon$. Such setting and adjustment of control variables are based on minimizing the Time-Scale Averaged Pressure Variance, defined for this controller to be a $0.2-\mathrm{Hz}$ low-pass version of the square-norm of $\boldsymbol{S}_{n}$.

Note: The pressure perturbations just upstream of the injector are highly correlated with the combustion pressure. So, they can be used as additional feedback to provide more active damping to the acoustic modes either inside the combustion zone or in the fuel-line. This can be done with a predictive damper as in the calculation of $u_{\mathrm{n}}^{d^{\prime}}$. Such dynamic equations for the predictor are far from being a physical model of the fuel-line dynamics. But, the actual correlation of the fuel-line with the combustion zone dynamics should nevertheless be adequately retained in the predicted states by virtue of the Kalman gain matrix.

\section{DESIGN EVALUATION AND EXPERIMENT}

The NASA Single Nozzle Combustor Rig (SNR) at UTRC was used as the experimental test bed for demonstrating closed-loop instability suppression using the MSPD controller. The SNR was operated at a pressure, temperature, and fuel-air ratio corresponding to a mid-power engine condition 
$\left(\mathrm{T} 3=770^{\circ} \mathrm{F}, \mathrm{P} 3=200 \mathrm{psia}\right.$, fuel-air ratio $=0.03$ ) and exhibited roughly the instability behavior shown in Figure 2.

\subsection{Simulation Models}

A reduced-order, parametric model and a "Sectored-1D" thermo dynamics flow model (Paxson ${ }^{25}$ ) of the SNR were used in the design and evaluation of the MSPD controller. The former is essentially a Helmholtz-type model of the two thermo-acoustics modes of the SNR, formulated in quadrature state variables similar to Equation (1-a) to (1-f) as follow:

$$
\begin{aligned}
& X_{n+1}=\mathrm{A} X_{n}+\mathrm{Q}\left(\tau_{\mathrm{a}} X_{n}, \tau_{\mathrm{b}} \widetilde{u}_{n}, \tau_{\mathrm{c}} p_{n}, w_{n}\right) ; \\
& p_{n}^{\prime a c^{\prime}}=\left[\begin{array}{llll}
c_{1} & 0 & c_{2} & 0
\end{array}\right] X_{n} \\
& S_{n}=p_{n}^{a c^{\prime}}+v_{n} \\
& {\left[\begin{array}{l}
p_{1} \\
p_{2}
\end{array}\right] \equiv\left[\begin{array}{llll}
\mathrm{h}_{11} & 0 & \mathrm{~h}_{12} & 0 \\
\mathrm{~h}_{21} & 0 & \mathrm{~h}_{22} & 0
\end{array}\right] \tau_{a}\left(X_{n}\right)+\left[\begin{array}{lll}
b & g & 1 \\
b & g & 1
\end{array}\right]\left[\begin{array}{c}
\tau_{b}\left(\tilde{u}_{n}\right) \\
\tau\left(p_{n}^{\prime} a \dot{c}\right) \\
w_{n}
\end{array}\right]}
\end{aligned}
$$

with limits : $-p_{\max } \leq p_{i} \leq p_{\max }$

$$
\begin{aligned}
& Q_{\mathrm{i}}=\kappa\left(\sqrt{\left(p_{i} / p_{o}\right)+1}-1\right) \quad(\text { for } i=1,2) \\
& Q \equiv\left[\begin{array}{llll}
0 & Q_{1} & 0 & Q_{2}
\end{array}\right]^{t}
\end{aligned}
$$

In equations $(10-\mathrm{a})$ to $(10-\mathrm{f})$, the state matrix $\mathrm{A}$ is as in expression (3). And,

$$
X_{\mathrm{n}} \equiv\left[\begin{array}{llll}
x_{1 n}^{1} & x_{2 n}^{1} & x_{1 n}^{2} & x_{2 n}^{2}
\end{array}\right]^{t} \text { stands for the } 4 \times 1 \text { state vector }
$$

of mode 1 and 2 (as superscripts); $p_{n}^{\prime a c^{\prime}}$ the static pressure oscillation about the mean static pressure $\bar{p}$ (of the operating condition in the combustion zone); $S_{n}$, sensed $p_{n}^{\prime a c^{\prime}}$; and $w_{n}, v_{n}$ are scalar, white disturbance and sensor noise limited to below $2000 \mathrm{~Hz}$. The heat-release fluctuation effect $Q$ is a vector-valued function of delayed states, fuel modulation command, $\widetilde{u}_{n}$, including valve dynamics, and disturbances. The operators $\tau_{a}, \tau_{b}, \tau_{c}$ are random time shifts (with non-zero mean values) applied on the respective variables. The effect of the combustion zone pressure oscillation on fuel modulation is too complex to model accurately; so, the terms involving $p_{n}^{\prime a c^{\prime}}$ and the constant gain " $g$ " are used here only for testing the robustness of the controller, not to be included in the predictor equation.

Remark: This plant model presents all the main challenges of the SNR: the thermal excitations modeled by the internal feedback matrix $\left\{\mathrm{h}_{i j}\right\}$, the time delay $\tau_{b}$ on control, phase drifts due to some randomness in the delays, and disturbances $w_{n}$.

\subsection{Control Validation Results}

The following parameter values of the reduced-order model for the HF-Configuration SNR are with PSI as the unit for the pressure feedback, Volt for the fuel-modulation command $u_{\mathrm{n}}$ to the servo valve used -- which was limited to 2 Volts in amplitude.

First, the measurement gain and the internal feedback gain for the dominant mode (Equation (10-b) and (10-d), respectively) are both normalized so that:

$\mathrm{c}_{22}=1 ;$ and $\mathrm{h}_{22}=1$.

With that normalization and units choice, the rest of model parameters are chosen to match empirical data for the sampling time $\mathrm{T}=0.0002$ seconds (i.e.; $5000 \mathrm{~Hz} \mathrm{I} / \mathrm{O}$ rate are used for both the reduced-order model and controller outputs on the rig):

$\mathrm{c}_{11}=0.8$;

$p_{o}=20 ; \kappa=0.6 p_{o}=12 ;$

$\mathrm{h}_{11}=1 ; \mathrm{h}_{12}=\mathrm{h}_{21}=0.1$;

$\bar{\tau}_{a}=0.0038 ; \bar{\tau}_{b}=0.0033 ; \bar{\tau}_{c}=0.0002$ (mean values);

$b=0.2322 ; \quad g=0.01$;

The rms value of $w_{n}$ is 0.2805 for the high disturbance

setting, and is 0.07 for low disturbance; that of $v_{n}$ is 0.07 .

The effect of fuel valve on the command $u_{n}$ is represented by a low-pass filter (resulting in $\widetilde{u}_{n}$ ) and an attenuation which is already absorbed into $b$.

The damping parameters $\zeta_{i}$ in the predictor (Equation (4-a) to (4-e)) and in Equations (1-a) to (1-c) for the Kalman matrix calculation were deliberately set at $30 \%$ of critical damping for both modes, not at the estimated values which is only about 0.03 for the HF mode. This is to ensure stability for the predictor with a simplified implementation of the Kalman feedback.

The validation results for the MSPD controller using this reduced-order model of the SNR are summarized in Figures 6 to 8. Figure $6 \mathrm{a}$ presents the Amplitude Spectra and Probability Density of combustor pressure oscillations with controller-on in comparison to the controller-off case, both with a much lower level of disturbances than in the SNR; however, this disturbance level is compatible to a known actual engine environment. Figures $6 \mathrm{~b}$ shows the favorable time- domain response of combustor pressure to the controller for this low-disturbance case, as the controller is turned $\mathrm{ON}$ and OFF alternately every 5 seconds. Figure 7 further 

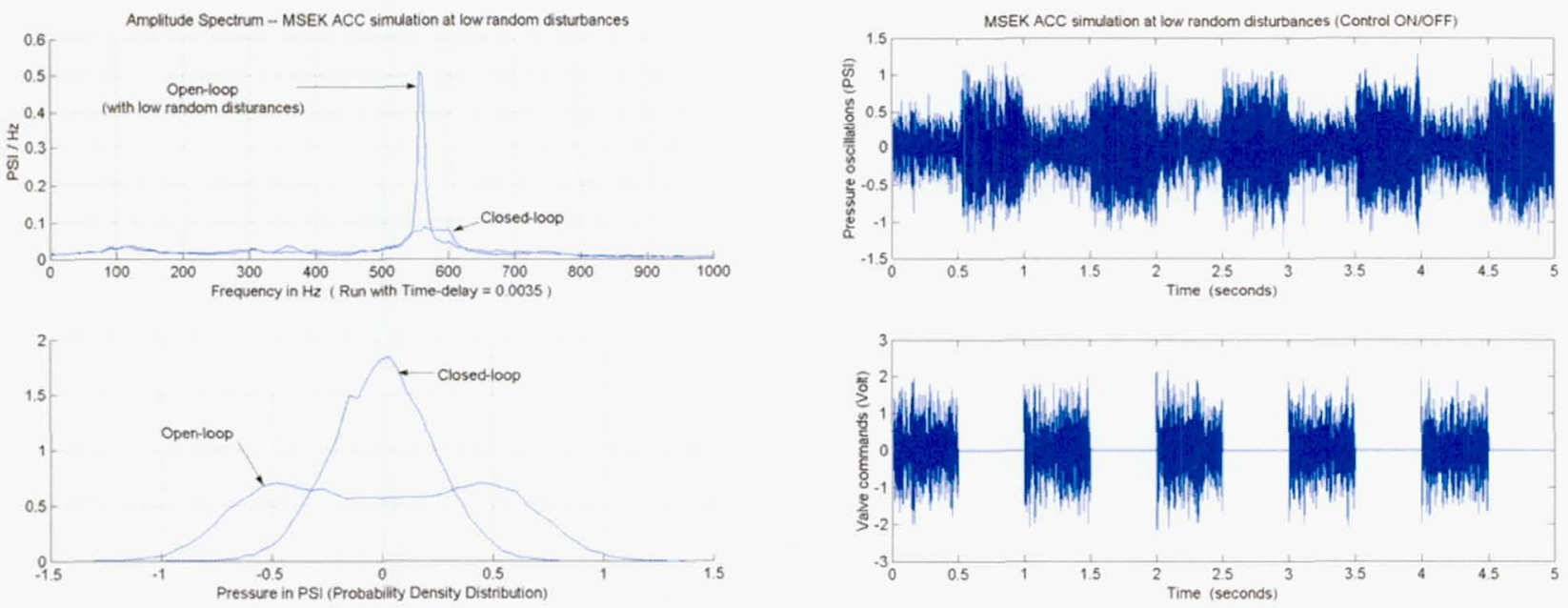

(a): Closed-loop versus open-loop combustion pressure oscillation Amplitude-Spectrum and Probability Density

(b): Pressure oscillations (top) and commands ON/OFF (bottom)

Figure 6: Simulation results with the reduced-order model at low random disturbance

demonstrates the absolute stability achieved by the controller (despite the large delay-time in control action) when there is no external disturbance, with the controller turned $\mathrm{ON}$ and OFF subsequently every 5 seconds. Lastly, Figure 8 presents the Amplitude Spectra and Probability Density of combustor pressure oscillations with controller-on in comparison to the controller-off case, both with a high level of disturbances comparable to the SNR environment.

\subsection{Experimental Results}

For the experimental demonstration of the MSPD controller, combustor pressure in the SNR was sensed about 2 inches downstream of the fuel injector. The control algorithms were implemented on a real-time processor. The fuel flow was dynamically controlled via a high-response fuel valve.

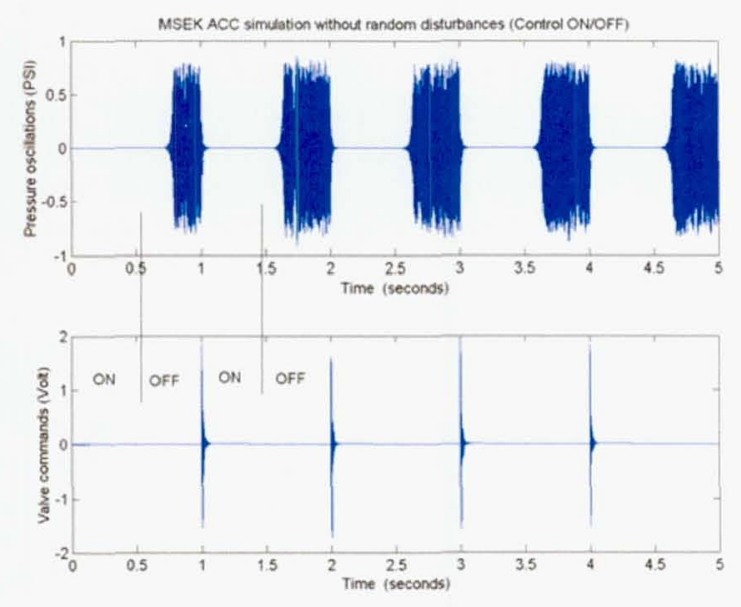

Figure 7: Pressure oscillations (top) and commands ON/OFF (bottom); simulated with the reduced-order model without disturbance
The significance of the "Predictor-based Damper" in the MSPD controller is mainly its effectiveness in supplying active damping to the acoustics modes. It is expected to be highly effective when the "background" disturbance level in the combustor is comparable to an engine environment such as Figure 2, not four times higher in Amplitude Spectra as in the SNR. But, it becomes less effective in the noisy environment of the SNR. This is when the "Tone Suppression" function in the controller becomes necessary. With Tone Suppression, the controller performs well, as predicted on the reduced order SNR model for the September 02 tests. On the other hand, although the nonlinear "Tone Suppression" part of MSPD has the most powerful effect on the PSD center peak, it needs the Damper to prevent "peak-splitting".
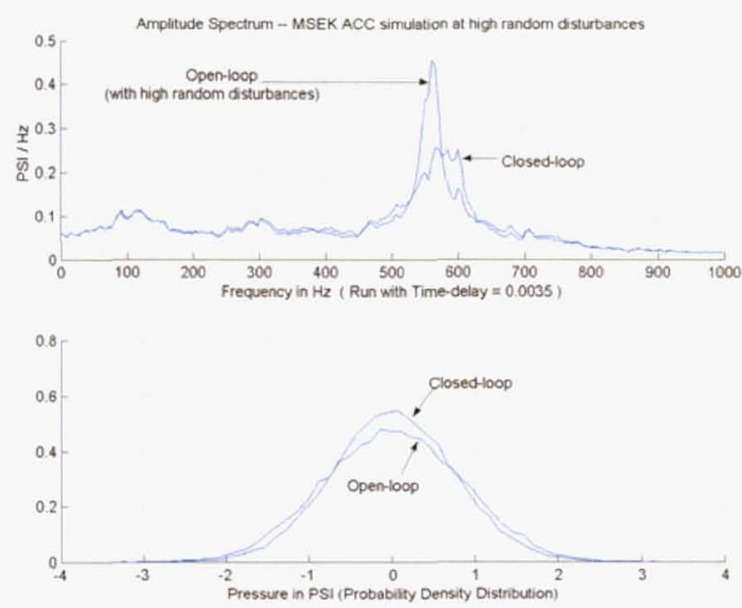

Figure 8: Closed-loop versus open-loop combustion pressure oscillation Amplitude-Spectrum and Probability Density; simulated with the reduced-order model at a high random disturbance 
Figure 9 shows the Amplitude Spectra of combustion pressure oscillations in an experiment with the MSPD controller on the Single Nozzle Combustion Rig; for comparison, this result is overlaid on that of the baseline instability (controller turned off). This result agrees with the earlier prediction on the reduced-order model. Both show about $30 \%$ reduction of pressure oscillation amplitude at the HF peak when the MSPD is used. The Upstream Compensation feature in the controller, however, has not been tested on the SNR.

Remark: Interestingly, the technique used in "Tone Suppression" was found also effective for massimbalance compensation in controlling magnetically levitated flywheels.

\section{GENERALIZED MSEK CONTROLLERS}

As mentioned previously, Houdre established the mathematics foundation for Wavelets representation of (non-trivial) random processes in $1993 .{ }^{20} \mathrm{~A}$ practical framework suitable for engineering applications of Multi-Scale-transformed random processes was introduced by $\mathrm{Le}^{21}$ in 1995 . Continuing in this direction, Equations (1-a) to (1-f) lend a useful example of Multi-scale building-blocks for the approximate formulation of system dynamics in Multi-Scales variables. The advantage of such approximate model is in the formulation of Kalman predictors or estimators of system transient characteristics with enhanced sharpness via Multi-Scale analysis. Quadratures evolution equations like (1-a) to (1-f) are suitable for the modal dynamics of acoustics, structures, rotors, etc. In general, the dynamics of multiple tones/modes can be approximated as such, using Compact Harmonics Wavelets Filter Banks, ${ }^{22}$ but probably with slightly more complex internal feedbacks (e.g., Equation (A4) in Appendix) and requiring more sophisticated, Extended Kalman filters. For

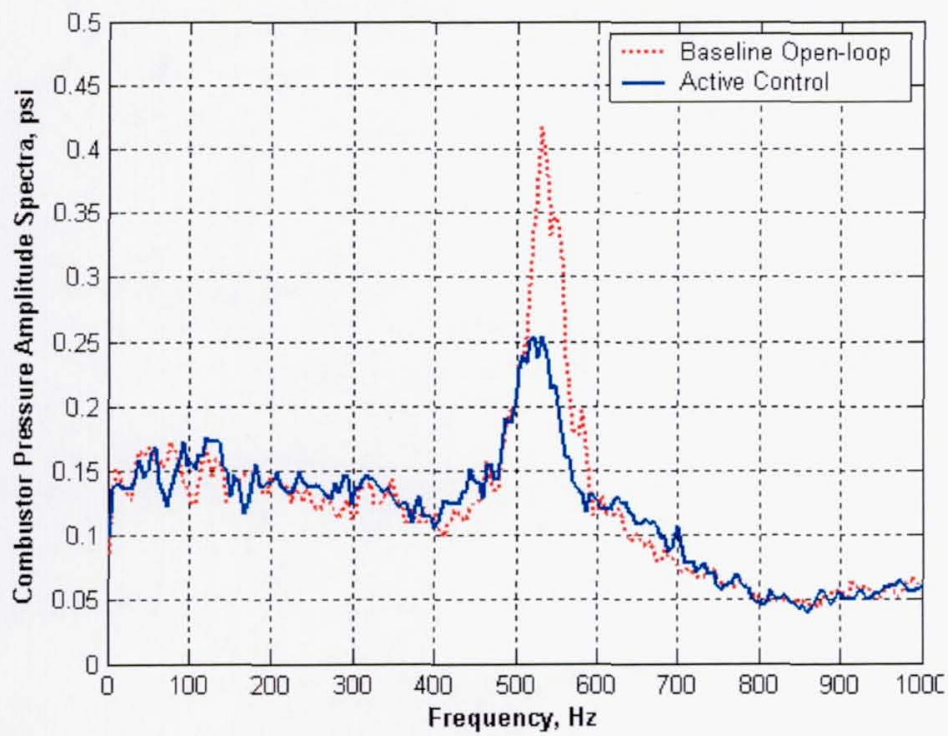

Figure 9: Amplitude Spectra showing the effects of active combustion control by the MSEK method over the combustion instability peak pressure oscillations

(9-11-02 SNR test) more deterministic systems, such as in flywheel magneticbearing control, physical-based (extended or conventional) Kalman filters and Multi-Scale techniques can still be integrated as in Figure 5 to effectively handle non-steady disturbances ${ }^{24}$. Furthermore, many types of modal dynamics, including those driven by non-stationary disturbances, could be approximated in such a way that optimal state-variables observers (to minimize the estimation errors covariance on the time-scale domain) exist in closed-form.

\section{CONCLUSIONS}

The Multi-Scale Extended Kalman (MSEK) approach has provided numerous capable, novel controllers for a wide range of control challenges in current research at NASA in innovative aerospace engines and power systems. The key to the versatility and effectiveness of the MSEK control approach is its innovative combination of Extended-Kalman Observers and Multi-Scale "features extraction" techniques for disturbance estimation, compensation, and performance optimization in real-time. In a recent demonstration of Active Combustion Control (ACC) with fuel modulation on a liquidfuel single-nozzle combustor rig, a MSEK controller suppressed high-frequency $(>500 \mathrm{~Hz})$ combustion pressure oscillations by $30 \%$. The combustor rig emulates an actual case of engine instability and operates at engine-realistic conditions. This demonstration and further analytical studies show the feasibility of the application of the MSEK approach to Active Combustion Control, which is an enabling technology for future aero-engine combustors with improved efficiency and reduced emissions.

\section{APPENDIX \\ Predicted Quadratures Evolution Model}

Each of the two possible acoustics modes in the NASA Single Nozzle Rig combustion chamber $(\sim 285 \mathrm{~Hz}$ and $>500 \mathrm{~Hz})$ is approximately a second order dynamics with low damping (about 3\% of critical damping for the dominant mode) and driven by the fluctuating heat release. The heat release has a very large time-delay for the desired control bandwidth, about 0.0035 seconds or more, as empirically determined. With added convection delays, the time lapse between sensed chamber pressure oscillations and the associated heat fluctuation could be more than 0.0038 seconds. Time-lag and saturation in heat-release are the important contributors to the sustained combustion acoustics. The effect of heat-release fluctuations on the combustion acoustics stays within certain determinable limits. Based on those assumptions, the following approximate "evolution model" for the combustion pressure quadratures at $N$ sampling steps ( control-delay time) ahead of the "current" time index " $n$ " is assumed for the formulation of a predictor:

$$
\begin{aligned}
& \boldsymbol{S}_{N+n+1}=\mathrm{A} \boldsymbol{S}_{N+n}+\mathrm{Q}\left(\boldsymbol{S}_{n+k}, u_{n}\right)+\mathbf{w} \\
& \mathbf{y}_{n}=\mathrm{M} \mathbf{S}_{n}
\end{aligned}
$$


In Equation (A1-a) and (A1-b), $\boldsymbol{S}_{n}$ denotes the $4 \times 1$ vector of the "quadrature pairs" $S_{n} \equiv\left[\begin{array}{c}S_{n}^{1} \\ S_{n}^{2}\end{array}\right]$ of tone 1 and tone 2 ( $\sim 285 \mathrm{~Hz}$ and $>500 \mathrm{~Hz}$, respectively); the superscript is the tone index and " $n$ " is the time index.

(Note: For simplicity, instead of a formal Orthogonal Wavelet Decomposition and Reconstruction scheme, a pair of Finite Impulse Response (FIR) band-pass filters can be suitably designed for each frequency band to extract the signal approximate "quadratures": One filter with a phase lead of 45 degrees at the center frequency of interest, and the other with a phase lag of 45 degrees; the gains of both filters are equal to 1 at the central frequency. The advantage of these "Quadrature Filters" is in their simplicity. The polar angle of the vector of extracted quadratures $\left[\mathrm{s}_{1}(\mathrm{t}) \mathrm{s}_{2}(\mathrm{t})\right]^{t}$ by such filters represents the instantaneous "phase" angle of a tone plus $\pi / 4$ radians -- $[\ldots]^{t}$ denotes a transposed matrix.)

The "output measurement" in Equation (A1-b) is a $2 \times 1$ vector $y_{n}$ representing the combined quadratures of mode 1 and mode 2 extracted from the sensed combustor pressure at time index " $n$ ". So:

$M=\left[\begin{array}{llll}1 & 0 & 1 & 0 \\ 0 & 1 & 0 & 1\end{array}\right]$

The quantities $\mathbf{W}$ is a band-limited random vector. The $4 \times 4$ "state-matrix" A in Equation (A1-a) represents only the dynamics of combustion chamber acoustics in modal representation, not including thermal excitations. Explicitly,

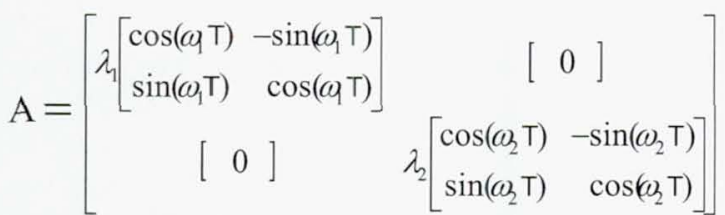

with $\mathrm{T}=0.0002$ seconds, the sampling time; and,

$\omega_{1}=570 \pi \mathrm{radians} / \mathrm{sec} ; \zeta_{1}=0.30 ; \lambda_{1}=\exp \left(-2 \zeta_{1} \omega_{1} \mathrm{~T}\right)$.

$\omega_{2}>1000 \pi \mathrm{radians} / \mathrm{sec} ; \zeta_{2}=0.03 ; \lambda_{2}=\exp \left(-2 \zeta_{2} \omega_{2} \mathrm{~T}\right)$.

The effect of combustion heat fluctuations on these acoustic quadratures (at $N$ steps ahead of $n$ ) is modeled as a certain vector-valued function $Q$ of the earlier acoustic states denoted by $\boldsymbol{S}_{k+n}$ and the fuel modulation command $u_{n}$ (with $k$ being a fixed integer much smaller than $N$ ). This vector-valued function is assumed of the form:

$$
Q\left(\boldsymbol{S}_{\mathrm{k}+n}, u_{\mathrm{n}}\right) \equiv\left[\begin{array}{llll}
0 & Q_{1} & 0 & Q_{2}
\end{array}\right]^{t},
$$

where the time-varying entries on the rhs are calculated using the following expressions of "effective modal excitations" $p_{1}$ and $p_{2}$ on fuel-flow variations and the acoustic states at time " $N+n$ ": $\left[\begin{array}{l}p_{1} \\ p_{2}\end{array}\right] \equiv\left[\begin{array}{llll}\mathrm{h}_{11} & 0 & \mathrm{~h}_{12} & 0 \\ \mathrm{~h}_{21} & 0 & \mathrm{~h}_{22} & 0\end{array}\right] \boldsymbol{S}_{n+k}+\left[\begin{array}{l}b \\ b\end{array}\right] u_{n}$,

where $\left\{\mathrm{h}_{i j}\right\}$ are constant, internal feedback gains, $b$ the approximate control gain. Also, $p_{i}$ 's (for $\mathrm{i}=1,2$ ) are subjected to:

$-p_{\max } \leq p_{i} \leq p_{\max } \quad($ for $\mathrm{i}=1,2)$

for a certain upper bound denoted $p_{\max }$. The respective unsteady heat effect $Q_{i}$ associated with these quantities $p_{i}$

(for $i=1,2$ ) are then approximated by:

$Q_{i}=\kappa\left(\sqrt{\left(p_{i} / p_{o}\right)+1}-1\right) \quad($ for $i=1,2)$

In Equation (A7), $P_{\mathrm{o}}$ is a reference pressure comparable to the mean pressure drop across the injector. The parameters $\left\{\mathrm{h}_{i j}\right\}, b, \kappa, p_{\max }$, and $N$ are chosen to match the open-loop forced response characteristics of the combustion chamber pressure.

Since $k$ (in Equations (A4) to (A7)) is small relative to $N$, it can be set to zero, so that $Q$ would be treated as a known input at time $n$. But, the large time-index shift from $\boldsymbol{S}_{N+n}$ to the feedback $\boldsymbol{y}_{n}$ is approximated by a 5th-order Pade approximation. That is, $\boldsymbol{y}_{n}$ is viewed as the result of a $5^{\text {th }}$ order Pade-transform (for a time-delay $\sim N \times \mathrm{T}, \mathrm{T}=0.0002$ seconds) applied on the $2 \times 1$ vector $M \boldsymbol{S}_{N+n}$. Consequently, instead of Equation (A1-b) the following state-space relationship between of $\boldsymbol{S}_{N}+n$ and $\boldsymbol{y}_{n}$ should be used with (A1-a) to derive a Kalman "estimator" (predictor) for $\boldsymbol{S}_{N+n}$ :

$$
\begin{aligned}
& \boldsymbol{z}_{n+1}=\mathrm{U} \boldsymbol{z}_{n}+\mathrm{FM} \boldsymbol{S}_{N+n} \\
& \boldsymbol{y}_{n}=\mathrm{E} \boldsymbol{Z}_{n}+\mathrm{DM} \boldsymbol{S}_{N+n}+\mathbf{v}
\end{aligned}
$$

where $\mathbf{V}$ is a band-limited random vector; and U, F, E, D are the combined state matrices of the pair of Padetransformations (with the respective dimensions $10 \times 10,10 \times 2$, $2 \times 10$, and $2 \times 2$ ). 


\section{REFERENCES}

[1] Lefebvre, A.H.: Gas Turbine Combustion, $2^{\text {nd }}$ edition, Taylor \& Francis, 1999.

[2] Brower, J., Ault, B. A., Bobrow, J. E., and Sumuelsen, G. S., 1990: "Active Control for gas Turbine combustors," the $23^{\text {rd }}$ International Symposium on Combustion, the Combustion Institute, Pittsburgh.

[3] Schadow, K., Yang, V., Culick, F., Rosfjord, T., Sturgess, G., and Zinn, B.: "Active Combustion Control for Propulsion Systems," AGARD Report 820, September 1997.

[4] Yu, K., Wilson, K.J., and Schadow, K.C.: "Active Combustion Control in a Liquid-Fueled Dump Combustor," AIAA Paper 97-0462, January 1997.

[5] Zinn, B.T. and Neumeier, Y.: "An Overview of Active Control of Combustion Instabilities," AIAA Paper 97-0461, January 1997.

[6] McManus, K.R., Magill, J.C., Miiller, M.F., and Allen, M.G.: "Closed-Loop System for Stability Control In Gas Turbine Combustors," AIAA Paper 97-0463, January 1997.

[7] Annaswamy, A.M., El Rifai, O.M., Fleifil, M., Hathout, J.P., and Ghoniem, A.F.: "A Model-based Self-tuning Controller for Thermoacoustic Instability," in Combustion Science and Tech., Vol 135, pp. 213-240, 1998.

[8] Whitelaw, J.H.: Combustion Oscillations, Extinction, and Control, final technical report, U.S. Army contract N6817197-C-9035, May 1998.

[9] Hibshman, J.R., Cohen, J.M., Banaszuk, A., Anderson, T.J., and Alholm, H.A.: "Active Control of Combustion Instability in a Liquid-Fueled Sector Combustor," presented at the International Gas Turbine \& Aero-Engine Congress and Exhibition, June 1999. ASME Paper 99-GT-215.

[10] Allgood, D., Campos-Delgado, D. U., Acharya, S., and Zhoo, K.: "Acoustic Control of Thermoacoustic Instabilities Using Experimental Model-Based Controllers," Proceedings of ASME Turbo Expo, New Orleans, LA, 2001.

[11] Johnson, C. E., Neumeier, Y., Nuemaier, M., and Zinn, B. T.: "Demonstration of Active Control of Combustion Instabilities on a Full-Scale Gas Turbine Combustor," Proceedings of ASME Turbo Expo, New Orleans, LA, 2001.

[12] Murugappan, S., Park, S., Acharya, S., Annaswamy, A. M., Gutmark, E. J., and Ghoniem, A. F., 2000: "Optimal Control of Swirl-Stabilized Combustor using System Identification Based Model," Turbine Conference, Cesme, Turkey.

[13] Murugappan, S., Acharya, S., Gutmark, E. J., and Messina, T., 1999: "Characteristics and Control of Combustion Instabilities in a Swirl-Stabilized Spray Combustor," the $35^{\text {th }}$ Joint Propulsion Conference and Exhibit, Los Angeles, CA.

[14] DeLaat, J.C., Breisacher, K.J., Saus, J.R., Paxson, D.E., 2000: "Active Combustion Control for Aircraft Gas Turbine Engines," $36^{\text {th }}$ Joint Propulsion Conference and Exhibition, Huntsville, AL.
[15] DeLaat, J. C. and Chang, C. T.: "Active Control of High Frequency Combustion Instability in Aircraft Gas-Turbine Engines," to be presented at the $16^{\text {th }}$ International Symposium on Air breathing Engines, Cleveland, Ohio, August 31September 5, 2003.

[16] Cohen, J.M. et al: "Experimental Replication of an Aeroengine Combustion Instability," International Gas Turbine and Aero-Engine Congress and Exhibition, Munich, Germany, 2000.

[17] Kopasakis, G.: "High Frequency Adaptive Instability Suppression Controls in a liquid-Fueled combustor", proposed for presentation at the $39^{\text {th }}$ Joint Propulsion Conference and Exhibit, Huntsville, Alabama, July 20-23, 2003.

[18] Jazwinski A. H., Stochastic Processes and filtering Theory, Mathematics in Science and Engineering Vol.64, Academic Press, 1970.

[19] Meyer Y., 1991, Wavelets: Algorithms and Applications, English translation and revision by Robert D. Ryan, SIAM edition 1994.

[20] Houdre, C., 1993, "Wavelets, probability, and statistics: Some bridges," Wavelets Mathematics and Applications (Studies in Advanced Mathematics), edited by J. J. Benedetto and Michael W. Frazier, GRC Press, 1994 edition.

[21] Le, D. K., "Multiscale System Identification and Estimation," Advanced Signal Processing Algorithm (1995), ed. F. Luke, SPIE Proceedings, vol. 2563.

[22] Le, D. K., Owen, A. K., Simon, D. L., 1997: "Wavelet Analysis of Air-Jet Injection Stall Control Effects in an AxiCentrifugal Gas Turbine Engine," AIAA paper 97-2774, $33^{\text {rd }}$ Joint Propulsion Conference, July 6-9, Seattle, WA.

[23] Misawa, E. A. and Hedrick, J. K.: " Nonlinear Observers - A State-of-the-Art Survey," Transaction of the ASME, Journal of Dynamic Systems, Measurement, and Control, Vol.111, pp 344-352, September 1989.

[24] Le, D. K. and Provenza, A.J.: "Tracking the PolarPrinciple Axis for Magnetic Bearing Control and Flywheel Balancing",Power Systems 2000 SAE Conference, 00PSC69 [25] Paxson , D.E.: "A Sectored-One-Dimensional Model for Simulating Combustion Instabilities in Premix Combustors," presented at the $38^{\text {th }}$ AIAA Aerospace Sciences Meeting \& Exhibit, Reno, Nevada, January 2000, NASA TM 1999209771, AIAA-2000-0313.

[26] Barooah, P., Anderson, T. J., and Cohen, J. M.: "Active Combustion Instability Control with Spinning Valve Actuator," Proceedings of ASME Turbo Expo, Amsterdam, Netherlands, 2002. GT-2002-30042.

[27] Annaswamy, A.M. and Ghoniem, A.F.: "Active Combustion Instability: Theory and Practice," IEEE Control Systems Magazine, December 2002, Vol. 22, Number 6.

[28] Le, D. K. and Provenza, A.J.: "An Observer-Based Magnetic Bearing Controller for Aerospace Flywheels," NASA Glenn Research Center 2001 Research and Technology Report (NASA TM 2002-211333). 
Public reporting burden for this collection of information is estimated to average 1 hour per response, including the time for reviewing instructions, searching existing data sources, gathering and maintaining the data needed, and completing and reviewing the collection of information. Send comments regarding this burden estimate or any other aspect of this collection of information, including suggestions for reducing this burden, to Washington Headquarters Services, Directorate for Information Operations and Reports, 1215 Jefferson Davis Highway, Suite 1204, Arlington, VA 22202-4302, and to the Office of Management and Budget, Paperwork Reduction Project (0704-0188), Washington, DC 20503.

\begin{tabular}{|l|l|l|}
\hline 1. AGENCY USE ONLY (Leave blank) & $\begin{array}{r}\text { 2. REPORT DATE } \\
\text { October } 2003\end{array}$ & $\begin{array}{r}\text { 3. REPORT TYPE AND DATES COVERED } \\
\text { Technical Memorandum }\end{array}$ \\
\hline
\end{tabular}

4. TITLE AND SUBTITLE

5. FUNDING NUMBERS

Control of Thermo-Acoustics Instabilities: The Multi-Scale Extended

Kalman Approach

6. AUTHOR(S)

WBS-22-708-28-09

Dzu K. Le, John C. DeLaat, and Clarence T. Chang

7. PERFORMING ORGANIZATION NAME(S) AND ADDRESS(ES)

National Aeronautics and Space Administration

John H. Glenn Research Center at Lewis Field

Cleveland, Ohio 44135-3191

8. PERFORMING ORGANIZATION

REPORT NUMBER

E-14100-1

9. SPONSORING/MONITORING AGENCY NAME(S) AND ADDRESS(ES)

10. SPONSORING/MONITORING
AGENCY REPORT NUMBER

National Aeronautics and Space Administration

Washington, DC 20546-0001

NASA TM-2003-212536-REV1

AIAA-2003-4934

11. SUPPLEMENTARY NOTES

Prepared for the 39th Joint Propulsion Conference and Exhibit cosponsored by the AIAA, ASME, SAE, and ASEE, Huntsville, Alabama, July 20-23, 2003. Responsible person, Dzu K. Le, organization code 7760, 216-433-5640.

12a. DISTRIBUTION/AVAILABILITY STATEMENT

Unclassified - Unlimited

Subject Category: 07

Distribution: Nonstandard

Available electronically at http://gltrs.grc.nasa.gov

This publication is available from the NASA Center for AeroSpace Information, 301-621-0390.

13. ABSTRACT (Maximum 200 words)

Multi-Scale Extended Kalman (MSEK) is a novel model-based control approach recently found to be effective for suppressing combustion instabilities in gas turbines. A control law formulated in this approach for fuel modulation demonstrated steady suppression of a high-frequency combustion instability $(>500 \mathrm{~Hz})$ in a liquid-fuel combustion test rig under engine-realistic conditions. To makeup for severe transport-delays on control effect, the MSEK controller combines a "wavelet"-like "Multi-Scale" analysis and an "Extended Kalman Observer" to predict the thermo-acoustic states of combustion pressure perturbations. The commanded fuel modulation is composed of a damper action based on the predicted states, and a tones suppression action based on the Multi-Scale estimation of thermal excitations and other transient disturbances. The controller performs automatic adjustments of the gain and phase of these actions to minimize the Time-Scale Averaged Variances of the pressures inside the combustion zone and upstream of the injector. The successful demonstration of Active Combustion Control with this MSEK controller completed an important NASA milestone for the current research in advanced combustion technologies.

\section{SUBJECT TERMS}

Active combustion control; Aircraft engines; Control; Combustion stability

15. NUMBER OF PAGES

17

17. SECURITY CLASSIFICATION
OF REPORT
Unclassified

18. SECURITY CLASSIFICATION
OF THIS PAGE
Unclassified
19. SECURITY CLASSIFICATION OF ABSTRACT
Unclassified

NSN 7540-01-280-5500 